\title{
A rare case of plantar lipoma
}

\begin{abstract}
Plantar tumors of soft tissue are rare and are characterized by their slow evolution, which delays the patient consultation period. Lipomas are among the most common benign tumors, which often serve in regions rich in fats, often in the face of the hands and feet. We report an exceptional case of plantar lipoma. Surgical treatment has laid the histological diagnosis of certainty and restores a normal and painless plantar support. Lipoma, despite its exceptional location at the foot level, should be mentioned as differential diagnosis of benign tumors of the foot.
\end{abstract}

Keywords: tumor, foot, lipoma, bones, radiographs
Volume 2 Issue 2 - 2018

Kaoutar Moustaide, Salim Gallouj, Aicha Nassiri, Fatima Zahra Mernissi

Department of Dermatology Venereology, Hospital Hassan II Fes, Morocco

Correspondence: Moustaide Kaoutar, Department of Dermatology Venereology, Hospital Hassan II Fes, Morocco, Email Kmoustaide@gmail.com

Received: February 18, 2018 | Published: April 05, 2018

\section{Introduction}

The tumors of the foot are rare. The soft tissue tumors are twice as common as those of bones in the foot and only a quarter of soft tissue tumors are malignant. The macroscopic clinical appearance has no specificity as to the histological nature; the inaccessibility of the plantar region and the thickness of the skin often delay the diagnosis of these tumors that are often taken to calluses, for fibromatosis or other benign tumors.

\section{Case report}

We report the case of a patient aged 42 who consults for swelling of the sole of the right foot painless, with a hyperkeratotic skin look, lasting for 4years with no history of trauma. The patient consulted because of the significant increase in the size of the swelling that caused a limp when walking. The clinical examination revealed a tumor of the right foot, hard, $5 * 4 \mathrm{~cm}$, mobile, with hyperkeratotic surface not painful on palpation. The lymph nodes were free and we noted a discrete lameness walking with a vicious attitude of the right foot (Figure 1). Radiographs of the foot face and profile was normal (Figure 2).

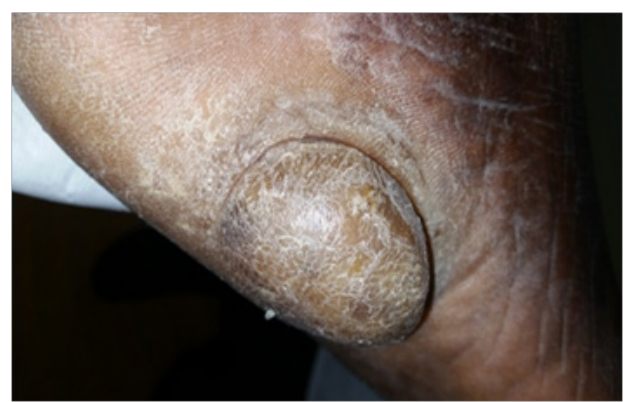

Figure I A plantar tumor.

The ultrasound showed a heterogeneous tissue formation, $38 * 46 \mathrm{~mm}$, non-vascular Doppler. The patient underwent surgery with removal of a lobulated and encapsulated mass measuring $3.8 \times 3 \times 4 \mathrm{~cm}$ whose dissection was easy then was sent for histological examination. The postoperative course was uneventful. A histological examination of the tumor showed epidermal coating acral type seat of a marked acanthosis with papillomatosis irregular anastomotique. It was stopped with a compact orthokeratosic marked hyperkeratosis above a granular layer. The epidermis shows no architectural abnormality or melanoma proliferation notable. The dermis underlying was conserved .Hypodermis morphology was underpinned by a proliferation. It was made of mature adipocytes arranged in lobules and separated from thick fibrous septats harboring vascular sections (Figure 3).

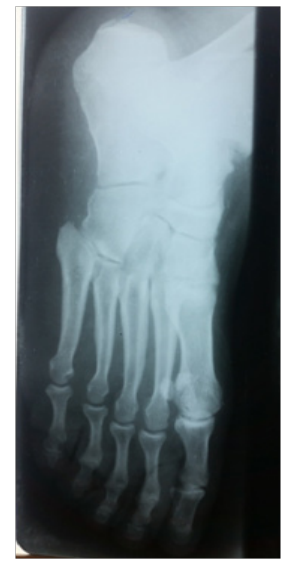

Figure $2 \mathrm{~A}$ normal face radiography of the foot.

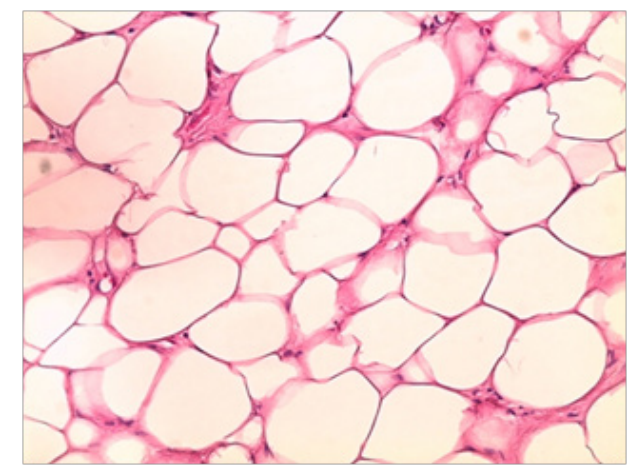

Figure 3 mature adipocytes arranged in lobules and separated from thick fibrous septats harboring vascular sections. 


\section{Discussion}

Tumors of plantar soft tissues are rare and characterized by slow and asymptomatic evolution which explains our patient consultation late. Lipomas are among the most common tumors of the soft tissue, they are composed of mature fat, however plantar localization is very rare. ${ }^{1}$ The clinical examination of the foot is difficult given the peculiarity of the skin is very thick at this level this makes diagnosis difficult plantar tumors hence the recourse to further examination. ${ }^{2}$ Plain radiographs can eliminate bone invasion. ${ }^{3}$ The main differential diagnosis is liposarcoma lipoma which differs from its with the size more than $5 \mathrm{~cm}$, and a tumour in the thigh or a subfascial tumour is relatively more likely to be a sarcoma. ${ }^{4}$ Surgical treatment is to ask the histological diagnosis of certainty and restore a normal and painless plantar support.

\section{Conclusion}

The tumors of the foot are rare and usually mild. Lipoma, despite its exceptional location at the foot level, should be mentioned as differential diagnosis of benign tumors of the foot.

\section{Acknowledgments}

None.

\section{Conflicts of interest}

The authors declared that there are no conflicts of interest.

\section{References}

1. Pontious J, Zielaskowski LA, King G. Extensive lipoma of the foot. $J A m$ Podiatr Med Assoc. 2003;93(5):402-405.

2. Kerman BL, Foster LS. Lipoma of the foot: a large and unusual case. $J$ Foot Surg. 1985;24(5):345-348.

3. Khatib K El, Lakouichmi M, Abouchadi A, et al. Lipome de la plante du pied : à propos d'une. 2009;54(1):71-74.

4. Rydholm A, Berg NO. Size, site and clinical incidence of lipoma:factors in differential diagnosis of lipoma and sarcoma. 1983;54(6):929-934. 